\title{
Primary Science: Knowing about the World through Science Process Skills
}

\author{
Kamisah Osman ${ }^{1}$ \\ ${ }^{1}$ Department of Educational Methodology and Practice, Faculty of Education, Universiti Kebangsaan Malaysia, \\ Selangor, Malaysia \\ Correspondence: Kamisah Osman, Department of Educational Methodology and Practice, Faculty of Education, \\ Universiti Kebangsaan Malaysia, 43600 UKM Bangi, Selangor, Malaysia. Tel: 60-3-8921-3858. E-mail: \\ kamisah@ukm.my
}

Received: September 20, 2012 Accepted: November 7, 2012 Online Published: November 30, 2012

doi:10.5539/ass.v8n16p1

URL: http://dx.doi.org/10.5539/ass.v8n16p1

\begin{abstract}
In the past three decades, science education has received increased attention at all level of schooling and continues to be a major concern at the present time. In the past, the new curriculum models for science at the elementary and secondary level proliferated, and although many of the models shared some element in common, they differed by placing an emphasis on either content, process, discovery learning or problem solving as the central focus of the curriculum. As the concern for improved science education was "thrust downwards", science educators were, and are, faced with similar decisions regarding science education in the early years; i.e. primary science. Although the process of scientific inquiry was frequently cited as a goal of science activities by some primary educators, the prime emphasis appeared to be on the acquisition of scientific concepts or content. This situation should be revamped because primary science is not just a matter of knowing about the world, but there is equally emphatic goal of helping children to behave as scientists. Therefore, this paper attempts to establish an overview of why scientific process skills should be emphasized at primary level. In achieving this aim, the value of teaching science and why it should be thought at primary level will be reviewed and the nature of children's idea will be explored.
\end{abstract}

Keywords: primary science, science process skills, scientific inquiry

\section{Introduction: Why Science?}

Science and the knowledge it produces is derived directly from the observation of phenomena and gives access to factual truth about the world through detached observation. Science, as argued by Hodson (1985) is a neutral activity unattained by socio-historical and economics factors to produce value-free knowledge and tests its propositions by means of objective and reliable experimental procedures. These characteristics of science lead to the implication that learning science will eventually help children to develop ways of understanding the world around them.

In the process of learning science meaningfully and effectively, children will not only have to build up concepts which enable them to knot the experiences together, but they must also learn ways of gaining and organizing information and of applying ad testing ideas. As a result, the children will not only equip themselves with the ability of making better sense of the physical entities around them, but also be prepared to deal more effectively with wider decision making and problem solving in their daily lives. More than that, science is also inextricably entwined with technology and has a particular role to play in developing "technological capability" (Bentley \& Watts, 1994; Layton, 1993). It is widely accepted that science and its daily application as an essential element in the preparation of young people for life in an advances technological society- where discoveries, inventions and developments not only seems to appear at an accelerating rate, but also play a larger and significant role. In a terse manner, Harlen $(1985$; p. 2) also stresses that "learning science can bring about double benefit because science is both a method and a set of ideas; both a process and a product"

The innovation and changes in the science curriculum across the globe since the last three decades have turned attention whether science should be taught at the primary level and how it should be taught. Despite recent curriculum development and countless effort that have been made to stimulate and support science teaching in primary level, the progress of science teaching in primary school all over the world has been very disappointing; 
the ideas and materials produced by curriculum development project have had little impact in the majority of schools (Russell, 1991; Peacock, 1993).

Therefore, it is important for those who concern with the innovation of science education to have a clear idea of why science is important in young children education so that, in the way we implement it, its purposes are actively furthered and expanded. It is always possible to teach to the 'letter of law' for instance without considering the nature and the spirit of the subject. However, it takes some effort to teach science because science is human endeavor, i.e.; along its path it engages with children's creativity as well as their imaginative capacity. It could also be argued that this effort will only be manifested meaningfully if the teacher is convinced of the value of teaching it and why it should be taught at the primary level.

\section{Why Science Should Be Taught and the Value of Teaching Science at the Primary Level}

A broad statement of the purpose of education as accepted worldwide is to fit the child for the society into which they will grow up. This statement bring to the conclusion that a prime reason for giving science a place in the curriculum from early childhood is the increasingly central part that it plays in the society especially in the developing countries where the scientific and technological changes grow tremendously and rapidly. Moreover, as indicated by Harlen (1993), being 'at ease' with key scientific ideas is a necessity to functioning in society as being 'at ease' with numbers, percentages or even with various form of languages.

Based upon the realization of the technological explosion that bring about an urgent need for a good preparation of tomorrow's decision makers and citizen, many countries stress the importance of introducing science at the elementary level. In the United Kingdom, for instance since the last twenty years all class teachers, without exception should include at least some science in their teaching (DES, 1985). The purposes as elaborated by Harlen (1992; p.492) are not only “...to teach children about science" but also "...develop the pupils' way of thinking towards a more scientific attitude from an earlier stage in order to be able to solve their social, parental and everyday life problems" (Orpwood \& Werdelin, 1987; p. 4).

There are several justifications about the value of teaching science at the primary level. Firstly, young children like scientists are curious about the world around them and in how and why things behave as they do. Naturally, there were usually rushed and their global representations biased towards their preconceptions rather than their perceptions. Researchers have shown that children's ideas of the world around them are being built during the primary year, whether or not they are taught science. However, without intervention to introduce a scientific approach in their exploration of the world, the ideas the children develop which are perceived as "misconception" or "alternative frameworks" (Driver, 1985) or "children ideas" (Osborne \& Freyberg, 1985) are "everyday" or "non-scientific", which arguably obstruct learning in science at the secondary level. Earlier, Osborne and Freyberg (1985) also proposed that:

1) Children approach to topics in their science lessons with quite firmly held ideas of their own, not with empty mind ready to fill with new ideas from their teacher;

2) Children's ideas are often different from scientific ideas used by their teachers and might well make better sense and seem more useful to children; and

3) Formal science lesson at the secondary school often leave children's own ideas untouched and as a result much of what is presented to them makes little sense

Secondly, the development of concepts and knowledge is not independent of the development of intellectual skills; unless children are helped to expand their ways of gathering and processing information, then a 'scientific approach' is difficult to achieve. This does not mean beginning to learn secondary science concepts at primary school, but exploring and investigating in such a manner that children's own ideas can be developed through scientific activities which include investigation of their physical and natural surroundings from early years (Ollenshaw \& Ritchie, 1993).

The third point about starting to learn science and to learn scientifically at the primary level is connected with fostering positive attitudes to the subject. Arguably, children attitudes to science are formed earlier than are their attitudes to most other subjects (Kuslan \& Stone, 1968; Harlen \& Kelly, 1989). Their capacity for abstract thought and for forming ideas about ideas comes earlier in the sciences than in many other areas of experiences through interaction with the concrete entities within their surrounding, which then affect their performance in secondary science. By nature, children don't explore, investigate, solve problems and form ideas only in school but they do these all the time. Their interest arising from their life at home or even holiday activities provide a starting point for work in science. In short, there is a wealth of experience for teacher $\mathrm{s}$ to draw on and nurture because most primary children undoubtedly are freely willing to share and discuss their enthusiasm in class. 


\section{The Development of Children's Ideas}

All children are architects of their own knowledge. They learn more about their environment by actively and spontaneously interact with the concrete entities within their physical and psychological culture through the process of equilibration or adaption (Piaget, 1985). Unconsciously and spontaneously every time we face with something new, in order to understand it meaningfully, we will search around in our mind and use our previous experience to fit the new materials into what is already known (Ausubel, 2000). Children go through the same process, even at an unsophisticated level in trying to make sense of new concrete experience presented to them. However, because of their limited experiences, they may not have an idea available to them which really fit and use only what is seems most reasonable to them. A view of how children learn has been widely discussed by Harlen $(1993 ;$ 1992). Based on her model, she suggests that learning is a process of changing ideas rather than taking in of ideas from scratch.

In explaining the development of children's ideas in science, Harlen (1993) suggested that a number of existing ideas which are already established in children's mind will be called upon whenever children are bombarded with new experience. In this stage, the students' logical reasoning, careful observation coupled with their creativity and imaginative power play crucial role. Obviously, which of these existing ideas that will be activated and linked to the new experience will depend on their physical similarities and also their existing vocabulary. Eventually, once the existing ideas have been linked, its usefulness in really explaining the new experience need to be tested. Then, the process of hypothesis testing which leads to a prediction, need to be done scientifically if the result is to be of value in making sense of the experience. This means that, more evidences have to be sought to find out whether it is consistent with predication based on linked ideas or on possible alternative ideas as a frame of reference (Driver, 1985).

There are three main possibilities of what may emerge as a result form the hypothesis testing: a) the linked idea is found to work and emerge unchanged, but strengthened by extension of its range; $b$ ) the idea does not work but can be made by some modification and so emerges as a modified ideas; $c$ ) it does not and cannot be made to work, in which case, the only way to try to make sense of the new experience is to start again and link existing ideas to it.

From the discussion, it can be concluded that the process of testing ideas are rigorous and systematic, in a way associated with scientific investigation and the process of scientific inquiry. This phenomenon bring to the conclusion that the extent to which ideas becomes more scientific depends on the way in which the linking and testing are carried out; i.e. on the use of process skills - observing, hypothesizing, predicating, investigating, interpreting and drawing conclusions. These skills are used in linking existing ideas to new experience, forming hypotheses and testing predications against new evidence. In short, the development of understanding in science depends crucially on the ability to carry out process skills in a scientific manner.

Thus, the development of process skills in primary education is important because of their important role in the development and pursuit of scientific knowledge (Millar \& Driver, 1987) and not just only because they are valuable skills in their own right. This is because the way in which the processes are carried out crucially influence the existing ideas which emerge spontaneously. However, it cannot be denied that, when the appropriate ideas do not emerge spontaneously, the process of observation, predication and investigation may still be carried out - but not in a scientific way: Observation may be confined ad narrowly focus on the evidence which confirms initial ideas; the prediction made will only involve a circular argument and not going beyond what is already known and set in the children intellectual horizon; and investigation may be carried out without fully considering all the variables that need to be taken into consideration.

As science educators, if we really want our children to achieve the aim of developing understanding of the world around them by fostering their scientific attitude and initiating their curiosity towards their environment, we must provide alternatives for change in both their ideas and their process skills. Therefore, in the next section, the generic components of scientific process skills will be defined and how teachers can use the knowledge of these processes as a framework for organizing a more systematic approach to science in primary level will be elaborated.

\section{The Science Process Skills}

Scientific processes are those processes of inquiry that form the basis to all scientific disciplines. It encompasses the processes scientists use in investigating the natural world; the cognitive processes involved in learning science and the pedagogical processes taking place in classroom (Millar \& Driver, 1987; Millar, 1994). Based on Gagne's (1965) definition of scientific processes, it can be inferred that scientific processes seem to be hierarchically organized; i.e. the ability to use the upper level process depend on the ability to use the simpler 
underlying process; each process is a specific intellectual skill used by all scientists and applicable to understand any phenomenon; each process is an identifiable behavior of scientists that can be learnt by students and the processes are generalisable across content domains.

Based on the nature of development of children's idea discussed in the previous sections, there are overlapping sets of process skills involved in the process of linking as well as testing ideas. Those involved in linking existing ideas in order to comprehended new experience has been extracted by Harlen (1992) as: observing, hypothesizing, predicting, planning and carrying out investigations, observing, interpreting findings, drawing conclusions and communicating. Among these processes, observing, hypothesizing, and predicting, investigating, drawing conclusion and communicating will be discussed because they are perceived as the most appropriate skills for science education in the early years (Lynn \& Newton, 1993).

\subsection{Observing}

For those who have had an experience working with the curious and enthusiastic five and six year old children, the opportunities for observation hardly need expanding. In reality, observation occurs all the time with little escapes from the eye of the young children. Even though it is simply an activity in which each of us, adult or children, do however need practice in organizing their observation. Scientific observation includes these following actions:

1) making use of several senses

2) noticing relevant details of the objects and their surrounding

3) identifying similarities and differences

4) discerning the order in which the events take place

5) using aids to the senses for study of details

By engaging in the process of scientific observation, children will be fully utilized all their senses appropriately and safely to gather relevant information and eventually develop their conceptual understanding towards the phenomenon being studied. Therefore, during the early development, children should be encouraged to make as many observations as they could so that they will be able to see as well as observe any phenomenon scientifically and productively- in the way scientists do.

\subsection{Hypothesizing}

Similarly in the case of the 'process' of hypothesizing, this activity just like observation is something which human do all the time. By definition, hypothesis is a statement put forward in an attempt to explain phenomena. When hypothesizing, the suggested explanation need not only to be correct, but it should also be reasonable in terms of the evidence available in terms of scientific concepts or principles. The indicators of hypothesizing include:

1) suggesting an explanation which is consistent with evidence

2) suggesting an explanation which is consistent with some scientific principle or concepts

3) applying previous knowledge in attempting an explanation

4) realizing that there can be more than one possible explanation of an event or phenomenon

5) realizing the tentative nature of any explanation

Therefore, we should bear in our mind that, what is of interest for science education especially in early childhood is not only the development of some general ability to hypothesis, but of some insight into scientific hypothesizing; i.e. the ability to generate hypothesis that employing scientific concepts besides having a particular purpose- provide general explanations about the behavior and characteristic of some part of the natural world.

\subsection{Predicting}

"What do you think might happen if...?" is an oft-repeated question in normal primary classroom. Although the correctness of the answer is not important for the children of this age, the opportunity and effort to begin to develop relationships based on their hypothesis or previous knowledge about what might happen in the future or what will be found that has not so far be found is important.

A prediction is quite different from a guess, which cannot be justified in terms of hypothesis or evidence. The behaviors which indicate that predicting is an action will include: 
1) making use of evidence from past or present experience in stating what may happen

2) explicitly using pattern in evidence to extrapolate or interpolate

3) justifying the statement about what will happen or to be found in terms of present evidence or past experience

4) showing caution in making assumptions about a pattern applying beyond the range of evidence distinguishing a prediction from guess.

\subsection{Investigating}

Investigation is often perceived as a primary method in helping young children see changes in objects. Superficially, the whole range of process skills are often regarded as "investigating: the setting up of a test for an idea. This process will include:

1) Deciding which variable is to be changed (independent) and which are to be kept the same (controlled)

2) Carrying out the manipulation of the variable so that the investigation is fair

3) Identifying which variable is to be measured or compared (dependent variable)

4) Making measurements or comparisons of the dependent variable using appropriate instruments

5) Working with an appropriate degree of precision

\subsection{Interpreting Findings and Drawing Conclusion}

As soon as the scientific data have been collected through the process of scientific observation, the process of interpreting findings and drawing conclusion is then followed.

By implementing these processes, the patterns of relationship between data can be seen and valuable conceptual framework can then be deduced. These processes not only involve putting various information together and finding patterns or trends in observation or result of investigation, but also include:

1) Identifying an association between one variable and another

2) Making sure that a pattern or association is checked against all the data

3) Showing caution in making assumption about the general applicability of a conclusion

\subsection{Communicating}

Obviously, in our routine and ritual activities, we are always communicating- not only to let others understanding our ideas, but tacitly help us to filter what we think and understand. In science, communication involves using various forms of representation- verbal and non-verbal which then help in organizing information and conveying it efficiently. Communication skills as suggested include:

1) Talking, listening or writing to sort out ideas and clarify meaning

2) Making notes of observations in the course of $n$ investigation

3) Using graphs, charts and tables to convey information

4) Choosing an appropriate means of communications using secondary sources of information

Based upon the view that school science can be made accessible to a much wider range of ability especially in primary school if it becomes less content laden and less abstract, in order to challenge and construct children existing ideas after eliciting them, scientific process skills must be exposed and introduced to them in every session of formal scientific conceptual instruction. Underpinning such an approach to the teaching of science is a number of assumptions:

1) Scientific processes are clearly definable and discrete. they can be used independently of each other

2) Processes are content free. they precede concepts, in the sense that their use leads to the discovery of new knowledge

3) Process skills are generalisable, transferable from one context to another and readily applicable in any context

This effort will not only help them to realize their own existing ideas but also their individual potential and hence navigate them to apply effectively and systematically their existing ideas to a new problem or situation. Therefore, the children will not only be able to polish their hidden potential but also reflect critically any sort of problems that being presented to them.

\section{The Role of Primary Teachers in Developing Scientific Process Skills}

The characteristics of scientific process skills discussed in the previous section carry with it implication for the 
role of primary educators. Active learning environment through observing, hypothesizing, predicting, investigating, interpreting findings and drawing conclusion and communicating presupposes teaching that stresses facilitation of learning rather than direct instruction. Teacher's role changes from one just presenting information to one of helping children to develop and use their own ideas.

The teacher who wishes to nourish active exploration and thus children's process skills must provide variety of materials: e.g. various sizes and shapes of block, car, truck, housekeeping equipment, sand, manipulative materials etc. It is necessary that these materials be placed so that children have access to them all the times. Teacher's role will include listening and watching, using open-ended questions to elicit further responses from children and giving them enough time to investigate and discuss their investigations. Type of questions such as "What do you think will happen?" or "Can you think of something else that you might use?" or "can you think of something else that acts like that?" will facilitate children to think, understand and explain the phenomenon being observed. However, teacher should not bombard children with a series of questions but allow time for questions and observation to come from children. In short, the activities in his/her classroom throughout the entire day become "the time" for science.

\section{Conclusion}

From the discussion, it can be concluded that are needs for science in primary education because it can make a countless contribution to children's understanding of the world around them and build up their ideas and using evidence that will help later learning in science. Eventually, it will nurture and engender more positive and thoughtful attitudes towards science as human activity. In teaching science, we are helping them to internalize the procedures and standards of the scientific community. Children need our assistance to construct for them a mental representation of the scientific ways of thinking and working. However, the experience of young children is limited; i.e. they are restricted in abstract and theoretical thinking: things that being presented to them have to be encountered in reality before they can be the subject of their thought and their mental manipulation.

Considering these factors and the nature of the development of ideas in children minds, the provision of direct experience with objects and events around them through scientific process skills activities is undoubtedly essential to their mental and intellectual development. And, of course, not all ideas are fruitful- there are successes as well as failure. However, it is worthwhile to take fully consideration about the matter being discussed in this paper if we are about to produce an all-rounded individual, a balances individual in terms of intellectual, spiritual, emotional and physical development.

\section{References}

Ausubel, D. P. (2000). The acquisition and retention of knowledge. London: Kluwer Academic Publishers.

Bentley, D., \& Watts, M. (1994). Primary science and technology. Buckingham: Open University Press.

DES. (1985). Science 5-16: A Statement of Policy. HMSO.

Driver, R. (1985). The pupil as scientist. Milton Keynes: Open University Press.

Gange, R. M. (1965). The psychological basis of science- a process approach. AAAS MiscellaneousPublication.

Harlen, W. (1985). Teaching and learning primary science. London: Harper and Row Pub.

Harlen, W. (1992). Research and development of science in the primary school. International Journal of Science Education, 14(5), 491-503. http://dx.doi.org/10.1080/0950069920140502

Harlen, W. (1993). Teaching and learning primary science (2nd ed.). London: Paul Chapman Pub.

Harlen, W., \& Kelly, S. (1989). Developing science in the primary classroom. Essex: Oliver and Boyd.

Hodson, D. (1985). Philosophy of science, science and science education. Studies in Science Education, 12, 25-57. http://dx.doi.org/10.1080/03057268508559922

Kuslan, L. I., \& Stone, A. H. (1968). Teaching children science: an inquiry approach. California: Wodworth Pub.

Layton, D. (1993). Technology challenge to science education. Buckingham: Open University Press.

Lynn, \& Newton, D. (1993). Investigation in national curriculum science: Some definition. Primary ScienceReview, 30, 15-17.

Millar, R. (1994). What is scientific method and can it be taught? In R. Levinson (Ed.), Teaching sceince. London: Open University Press.

Millar, R., \& Driver, R. (1987). Beyond process. Studies in Science Education, 14, 33-62. http://dx.doi.org/10.1080/03057268708559938 
Ollerenshaw, C., \& Ritchie, R. (1993). Primary science: Making it work. London: David Fulton Pub.

Orpwood, G., \& Werdelin, I. (1987). Science and technology in primary school of tomorrow. Paris: UNESCO.

Osborne, R., \& Freyberg, P. (1985). Learning in science: The implication of children's science. Hong Kong: Heinemann.

Peacock, A. (1993). A global core curriculum for primary science. Primary Science Review, 28, 8-9.

Piaget, J. (1985). Equilibration of cognitive structure. Chicago: University of Chicago Press.

Russel, T. (1991). Primary science and the clash of cultures in developing country. In A. Peacock (Ed.), Science in Primary School- Multicultural Dimension. London: MacMillian Education. 